$\mathrm{Nr} 2(65), 2020$, s. 133-141

https://doi.org/10.12797/Politeja.17.2020.65.10

\author{
Kamila ŁAPICKA \\ Uniwersytet Warszawski \\ colendra@wp.pl
}

\title{
NIEPRZERWANY ŻYWOT INKWIZYCJI \\ HISZPAŃSKIEJ - STUDIUM \\ PRZYPADKU Z ESTREMADURY
}

ABSTRACT The Neverending Story of the Spanish Inquisition - a Study of a Case from Extremadura

The subject of this research is the book 'El pecado nefando del obispo de Salamina' (The deplorable sin of the bishop of Salamina) written in 2002 by the Spanish historian Francisco Núñez Roldán. In the context of post-memory I am interested in the origins of this book, which are connected with the Spanish Inquisition and the attempts to regard its author as a secondary witness. It is also important that the activities of the Holy Office (1478-1834) are not only the subject of continuing historical research but are also a rich source of inspiration for artists and scholars.

Key words: post-memory, Spanish Inquisition, archives

Słowa kluczowe: postpamięć, Inkwizycja hiszpańska, archiwum 


\section{JAK GŁĘBOKO SIĘGA POSTPAMIĘĆ?}

W roku 2014 hiszpańska badaczka, Laia Quílez Esteve opublikowała artykuł pt. $\mathrm{Ha}$ cia una teoría de la posmemoria. Reflexiones en torno a las representaciones de la memoria generacional (Wokól teorii postpamięci. Refleksje na temat reprezentacji pamięci międzypokoleniowej), który skłonił mnie, by, myśląc o postpamięci, wyjść poza obszar historii XX wieku i zastanowić się nad wpływem, jaki wywiera na historię, literaturę i teatr Hiszpanii jedna z emblematycznych instytucji tego kraju, która zakończyła działalność blisko dwieście lat temu.

Zdaniem Quílez Esteve znajdujemy się obecnie w epoce kommemoratywnej, czy też $\mathrm{w}$ epoce nostalgii ${ }^{I}$. Teraźniejszość łączy się w niej z przeszłością na wiele sposobów, kwestionując pamięć oficjalną znanych wydarzeń historycznych, domagając się odzyskania pamięci wydarzeń przemilczanych oraz tworząc w przestrzeni publicznej kolejne miejsca pamięci - pomniki, muzea, tablice. Pamięć i historia stają się także „tworzywem" artystów. W obszarze literatury niesłabnącą popularnością cieszą się powieści historyczne, a także wszelkie gatunki (auto)biograficzne, zaś w teatrze z powodzeniem są wystawiane dramaty historyczne. Pamięć jest w nich obecna w wielu wymiarach i często pojawia się w kontekście wielkich konfliktów, z których w Hiszpanii najistotniejszym jest wciąż wojna domowa (1936-1939).

Laia Quílez Esteve sytuuje postpamięć w szeregu współczesnych dyscyplin badawczych z przedrostkiem ,post”, takich jak: posthumanizm, postkolonializm, posthistorycyzm. Tym samym wpisuje tę strukturę przekazu traumatycznej wiedzy i doświadczenia ${ }^{2}$ w tkankę postmodernistycznego społeczeństwa, dla którego charakterystyczne są nie tylko fragmentaryczność, cytowanie, intertekstualnośc i refleksja nad dyskursami, które wytwarza $i$ ksztattuje $e^{3}$, ale także kryzys wiary w możliwości poznania i dotarcia do prawdy obiektywnej. W kwestii zasięgu oddziaływania postpamięciowego dyskursu Quílez Esteve zajmuje podobne stanowisko, jak Marianne Hirsch, która wyjaśnia swoją koncepcję następująco: Postpamięć charakteryzuje doświadczenie tych, którzy dorastali zdominowani przez narracje poprzedzajace ich narodziny. Ich wtasne, spóźnione historie zostaty zastapione przez historie poprzedniej generacji, uksztattowane przez traumatyczne wydarzenia, których nie można w petni zrozumieć ani odtworzyć. Rozwijatam to pojęcie w relacji z dziećmi ocalonych z Holokaustu, ale myśle, że może być użyteczne do opisu pamięci drugiego pokolenia $w$ zwiazku z wydarzeniami lub doświadczeniami innej kulturowej lub zbiorowej traumy ${ }^{4}$.

L. Quílez Esteve, Hacia una teoría de la posmemoria. Reflexiones en torno a las representaciones de la memoria generacional, „Historiografías” 2014, nr 8, s. 59. Jeśli nie jest podane nazwisko tłumacza, wszystkich przekładów na język polski (z języka hiszpańskiego lub angielskiego) dokonała - podobnie jak tu - autorka artykułu.

2 Postpamięć nie jest ruchem, metodą czy idea; postrzegam ją raczej jako strukture wewnatrz-i ponadpokoleniowego przekazu traumatycznej wiedzy i doświadczenia. M. Hirsch, The Generation of Postmemory, „Poetics Today” 2008, vol. 29, nr 1, s. 106.

3 L. Quílez Esteve, Hacia una teoría..., s. 64.

4 M. Hirsch, Past Lives: Postmemories in Exile, „Poetics Today” 1996, vol. 17, nr 4, s. 662. Hirsch dokonała podziału na „postpamięć rodzinną” (familial postmemory) i „postpamięć afiliacyjną” (affiliative 
Hirsch zdaje sobie sprawę, że w drugiej dekadzie XXI wieku, po okresie dyktatur w Ameryce Łacińskiej, a także w obliczu konfliktów, które miały miejsce w Bośni, Darfurze czy Izraelu, Holokaust nie może być dtużej przypadkiem granicznym w dyskusji o historycznych traumach, pamięci i zapomnieniu ${ }^{5}$. Laia Quílez Esteve dodaje, że postpamięć jako kategoria analizy może nam pomóc zrozumieć sposoby transformacji, którym ulegała traumatyczna pamięć np. wojny w Wietnamie, ludobójstwa popełnionego w Kambodży przez Czerwonych Khmerów, a w obszarze hiszpańskim - wojny domowej i reżimu frankistowskiego ${ }^{6}$.

Przywołane wypowiedzi skłaniają do zadania pytania: Jak głęboko sięga postpamięć? Większość wydarzeń historycznych, o których była mowa, rozegrała się w wieku XX, co oznacza, że wciąż mogą żyć ich uczestnicy, a także ich dzieci i wnuki - depozytariusze postpamięci rodzinnej. W jaki sposób ta sytuacja zmieni się w kolejnym stuleciu? Czy przestaniemy rozpatrywać wspomniane, traumatyczne zdarzenia w kategorii postpamięci, zastępując je nowymi doświadczeniami historycznymi? Można się także zastanawiać, na ile postpamięć jest zjawiskiem uniwersalnym, a została tylko nazwana w XX wieku i prawomocne jest mówienie np. o postpamięci wojen napoleońskich?

Ograniczmy się jednak do obszaru Hiszpanii. Quílez Esteve wspomniała już o wojnie domowej i dyktaturze generała Franco. Ja chciałabym dodać do hiszpańskiego dyskursu postpamięciowego trzeci modul: Inkwizycję hiszpańską.

\section{HISTORIA I LEGENDA INKWIZYCJI}

Inkwizycja hiszpańska została powołana do życia z inicjatywy Królów Katolickich, na mocy bulli fundacyjnej papieża Sykstusa IV z 1 listopada 1478 roku. Jako sad podlegata królowi i posiadata najwyższa wtadzę w sprawach zwiąanych ze zwalczaniem herezji i przywracaniem wśród wiernych postuszeństwa Kościotowi ${ }^{7}$. Opierając się na ustaleniach Jeana-Pierre'a Dedieu, Helen Rawlings charakteryzuje cztery fazy funkcjonowania Inkwizycji. W pierwszej (1480-1525) uwaga inkwizytorów była skupiona na ściganiu żydowskich konwertytów praktykujących w ukryciu dawną wiarę. W drugiej (15251630) przedmiotem dochodzeń stały się również: herezja protestantyzmu, wykroczenia religijne morysków oraz odstępstwa od katolickiej ortodoksji (np. bluźnierstwa,

postmemory), rozwijając koncepcję Evy Hoffman, która zarysowała linię podziału między postpokoleniem jako catościa i literalnie rozumianym drugim pokoleniem. E. Hoffman, After Such Knowledge, New York 2004, s. 187. „Postpamięć rodzinna” ma charakter wewnątrzpokoleniowy i wertykalny - dotyczy przekazu traumatycznej pamięci i doświadczeń pomiędzy rodzicami a dziećmi. „Postpamięć afiliacyjna” ma charakter ponadpokoleniowy i horyzontalny. Kształtuje się w wyniku życia jednostki w tym samym momencie dziejowym, co konkretne drugie pokolenie, w potaczeniu ze strukturami zapośredniczenia, które sa na tyle akceptowalne, dostępne oraz istotne, by objąc większa grupę organiczna siecia transferu. M. Hirsch, The Generation of Postmemory, s. 114-115.

5 M. Hirsch, The Generation of Postmemory: Writing and Visual Culture After the Holocaust, New York 2012, s. 18.

6 L. Quílez Esteve, Hacia una teoría..., s. 73.

7 H. Rawlings, Inkwizycja hiszpańska, przeł. M. Piątek, Kraków 2009, s. 31. 
sodomia). W trzeciej (1630-1725) ponownie głównymi podejrzanymi zostali krypto-Żydzi, a w czwartej (1725-1834) aktywność trybunału zmalała, zaś sprawy dotyczyły głównie moralności ${ }^{8}$.

Mimo zakończenia swego formalnego istnienia, Inkwizycja zyskała drugie życie jako mit, inspirując artystów i badaczy. Zdaniem Doris Moreno, autorki artykułu $\mathrm{La}$ construcción del mito de la Inquisición, Inkwizycja stała się punktem odniesienia w dyskusjach o wszelkiego typu nietolerancji - religijnej, politycznej, społecznej oraz dotyczącej swobody twórczej. Do powstania „czarnej legendy” Inkwizycji, która zaczęła się rodzić w XVI wieku, znacząco przyczynity się relacje prześladowanych protestantów. Jak podkreśla Henry Kamen: Przeciwko trybunatowi zostata wykorzystana prasa drukarska, jedna z najważniejszych broni reformacji. W roku 1567 ukazała się książka Sanctae Inquisitionis Hispanicae Artes, napisana pod pseudonimem Reginaldus Gonzalvus Montanus przez dwóch protestanckich wygnańców z Hiszpanii. Fakt, że kształtujący obraz okrutnej Inkwizycji autorzy byli naocznymi świadkami jej działalności, sprawił, że ich dzieło było chętnie czytane w przekładach na wiele języków, m.in. angielski, niemiecki i holenderski. Kamen dodaje, że antyinkwizycyjną propagandę tworzono także we włoskich prowincjach Korony hiszpańskiej, gdzie obawiano się wprowadzenia hiszpańskiego trybunału. Raporty włoskich dyplomatów przebywających na Półwyspie Iberyjskim potęgowały ów strach. W 1563 roku ambasador Tiepolo opowiadat, że każdy wzdryga się na jej nazwę, gdyż inkwizycja ma catkowita wtadze nad majątkiem, życiem, honorem, a nawet duszami ludzi ${ }^{10}$. Antyhiszpańską kampanię prowadzono również w Niderlandach i w Anglii, gdzie drukowano propagandowe ulotki i broszury. Siła słowa drukowanego była na tyle duża, że można było odnieść wrażenie, iż protestanccy męczennicy stanowili główny obiekt prześladowań Świętego Oficjum, podczas gdy większość jego ofiar była pochodzenia żydowskiego. Kamen stwierdza, że dopiero w XIX wieku oceniono właściwie antyżydowski aspekt działalności trybuna$\mathrm{fu}^{11}$. Powstały ważne prace historyczne, akcentujące rolę Żydów w Hiszpanii, m.in. History of the reign of Ferdinand and Isabella W.H. Prescotta (1838) oraz Historia social, politica y religiosa de los judios de España y Portugal (1875-1876), w której José Amador de los Ríos, mimo poczattowej sympatii dla sprawy żydowskiej, przechylat się stopniowo ku usprawiedliwieniu wygnania jako nieuniknionej ceny, która państwo musiato zaptacić za utrzymanie swej jedności $i^{12}$. W XIX i na początku XX stulecia pojawiły się publikacje pretendujące do miana kompendiów na temat działalności Inkwizycji hiszpańskiej Histoire Critique de l'Inquisition Juana Antonia Llorente (1817), pierwsza praca oparta na krytycznej analizie źródel, oraz A History of the Inquisition (1906-1908) Henry'ego Charlesa Lea. Tę ostatnią pozycję Henry Kamen uważa za ostateczną wersję historii

Tamże, s. 23-30.

9 H. Kamen, Inkwizycja hiszpańska, przeł. K. Bażyńska-Chojnacka, P. Chojnacki, Warszawa 2005, s. 281.

10 Tamże, s. 284.

11 Tamże, s. 286.

12 R. García Cárcel, La herencia del pasado. Las memorias históricas de España, Barcelona 2011, s. 389. 
Inkwizycji ${ }^{13}$. Dziś natomiast wiele osób za modelową uznaje jego pracę The Spanish Inquisition. A Historical Revision (1997), która po polsku ukazała się w roku 2005 pt. Inkwizycja hiszpańska.

\section{ODZYSKIWANIE HISTORII LOKALNEJ}

Utwór, który będzie głównym przedmiotem moich rozważań, nosi tytuł El pecado nefando del obispo de Salamina (2002), co można tłumaczyć jako „Ohydny grzech biskupa Salaminy”. Jego autorem jest Francisco Núñez Roldán, emerytowany profesor historii nowożytnej Uniwersytetu w Sewilli, zaś geneza jego publikacji jest dziełem szczęśliwego przypadku. Przygotowując się do wystąpienia konferencyjnego na zupełnie inny temat, badacz trafił na źródła, które zafrapowały go na tyle, że napisał książkę w duchu mikrohistorii. Mowa o legajo 4472, znajdującym się w sekcji prawnej archiwum Pałacu Arcybiskupiego w Sewilli. Zawierało ono dokument datowany na rok 1579, złożony z ponad trzystu zszytych folios. Ku zaskoczeniu historyka okazało się, że są to akta procesu wytoczonego bratu Francisco de Salazarowi, franciszkaninowi, biskupowi Salaminy, za sodomię. Przestępstwo, za które osądzono biskupa i jego pazia, Lorenza de Santasa Martasa, zostało zgłoszone 28 lipca 1578 roku inkwizytorom z trybunału w Llerenie. Donos złożył Diego Ximón, morysek, gospodarz, który przyjął biskupa i jego świtę w swoim domu w Campillo de Llerena, gdy biskup był w drodze do Sewilli. Inkwizytorzy przesłuchali Ximóna i poinformowali o jego zeznaniach inkwizytora generalnego, a ten króla Filipa II, który wyznaczył swego pełnomocnika i upoważnił go do zatrzymania pazia, przeprowadzenia śledztwa (w trakcie którego poddano go torturom) i wydania na niego wyroku. Zlecił mu także trzymanie pod strażą biskupa Salaminy w klasztorze św. Franciszka, choć wedle ustaleń, które zapadły na niedawnym w stosunku do omawianych wydarzeń soborze trydenckim, prawo do wydania takiej decyzji miał tylko papie $\dot{Z}^{14}$.

Zaskoczenie Núñeza Roldána wynikało nie z charakteru popełnionego przestępstwa, bardzo pospolitego w szesnastowiecznej Sewilli, tylko z rangi osobistości, jaka je popełniła - był to biskup Kościoła - oraz z rangi sędziego, który wszczął proces podlegający prawu kanonicznemu ${ }^{15}$. Był nim arcybiskup Sewilli Cristóbal de Rojas y Sandoval ${ }^{16}$, który został wyznaczony do takiej roli na mocy papieskiego breve, wydanego przez Grzegorza XIII w lutym 1579 roku. Breve upoważniało arcybiskupa Sewilli do uwięzienia biskupa Salaminy i wyznaczenia prokuratora, który zajmie się zbadaniem sprawy, wytoczeniem procesu i powołaniem świadków. Gdyby arcybiskup Sewilli uznał

H. Kamen, Inkwizycja..., s. 287.

14 Zob. Kanon 5 ustanowiony w trakcie sesji 24, która odbyła się 11 listopada 1563 roku. Dokumenty Soborów Powszechnych: tekst taciński i polski. T. 4, (1511-1870): Lateran V, Trydent, Watykan I, oprac. A. Baron, H. Pietras, przeł. A. Baron et al., Kraków 2004, s. 745.

15 F. Núñez Roldán, El Pecado Nefando del Obispo de Salamina. Un Hombre sin Concierto en la Corte de Felipe II, Sevilla 2002, s. 11-12.

16 Po jego śmierci w roku 1580 sprawę zakończył kolejny biskup Sewilli, Rodrigo de Castro. 
biskupa Salaminy winnym sodomii, mógłby zaordynować jego degradację, a nawet przekazanie biskupa i jego wspólników ramieniu świeckiemu. Było to śmiertelnie niebezpieczne, jak przekonał się o tym wspominany paź biskupa, Lorenzo de Santas Martas, skazany w marcu 1579 roku na śmierć przez uduszenie garotą i spalenie na stosie. Był to piętnastoletni chłopiec z ubogiej rodziny, który pełnił posługi dla rozmaitych ludzi Kościoła. Podczas przesłuchania królewski pełnomocnik obiecał puścić go wolno za wyjawienie prawdy, tzn. potwierdzenie, że łączyły go z biskupem stosunki cielesne, jednak nie dotrzymał słowa.

Istotne jest także, że obaj oskarżeni podlegali innej jurysdykcji: paź - królewskiej, zaś biskup - kościelnej. Francisco Núñez Roldán odnalazł akta obu spraw, ponieważ kościelny wymiar sprawiedliwości poprosił o dostarczenie akt sprawy pazia. Proces biskupa - oskarżonego o sodomię, bluźnierstwa i symonię - zakończył się w grudniu 1583 roku. Zgodnie z wyrokiem duchowny miał przez dwadzieścia lat pozostawać w celi klasztoru św. Franciszka, skąd mógł wychodzić tylko na niedzielną mszę; nie mógł także sprawować obowiązków kapłańskich.

W roku 2015 dokonano adaptacji teatralnej książki Núñeza Roldána i wystawioną ją pt. El Obispo de Salamina („Biskup Salaminy”) w Campillo de Llerena ${ }^{17}$. Jak pamiętamy, to właśnie w tej gminie położonej w Estremadurze i liczącej dziś około tysiąc czterystu mieszkańców, rozgrywały się wydarzenia opisane w utworze. Celem inscenizacji było z jednej strony odzyskanie fragmentu historii lokalnej, z drugiej zaś - przybliżenie atmosfery rządów Filipa II oraz ukazanie modus operandi Inkwizycji hiszpańskiej. Funkcję teatru spełniał miejski stadion piłkarski, zaś jako aktorzy i statyści wystąpili członkowie lokalnej społeczności. Próby do tej wieloobsadowej, plenerowej realizacji trwały cztery miesiące. Wyreżyserowat ją Isidro Leyva, znany w Estremadurze z odtwarzania historii lokalnej na sposób teatralny przy udziale aktorów amatorów oraz w naturalnej scenerii. Przedstawienie przygotowano z inicjatywy władz gminnych, które podejmują różnorodne działania służące przypominaniu historii regionu, począwszy od starożytności, gdy był on ostoją bogactwa i dobrobytu.

\section{POŁĄCZENIE Z PRZESZŁOŚCIĄ}

Czy możemy powiedzieć, że źródła historyczne także funkcjonują jako medium postpamięci afiliacyjnej, kiedy wiodą do przedstawienia narracyjnego, jakim jest wybrana przeze mnie książka? Z oczywistych powodów hiszpański badacz nie mógł korzystać $\mathrm{z}$ fotografii, $\mathrm{z}$ archiwum historii mówionej czy z retransmisji procesu. Nie umieścił w swojej książce żadnych rycin ani obrazów, a sądząc po skrupulatności jego pracy, wnioskuję, że ich po prostu nie znalazł. Mimo to postanowił poddać przeszłość reanimacji, ożywić ją, jak pisze Marianne Hirsch w odniesieniu do fotografii jako niezwykle

17 Informacje na temat premiery, która odbyła się 2 VIII 2015 roku, pochodzą z artykułu Campillo de Llerena rescata en una obra de teatro la historia del Obispo de Salamina ante la Santa Inquisición, „El Diario” 2015, 27 VII, [online] https://www.eldiario.es/eldiarioex/cultura/Campillo-Llerena-Obispo-Salamina-Inquisicion_0_413659070.html, 21 VIII 2018. 
skutecznego medium postpamięci ${ }^{18}$. Sądzę, że istotna jest także motywacja badacza przyznał, że napisał książkę dla siebie oraz kilku przyjaciół i jest ona „dzieckiem pragnienia", a nie potrzeby ${ }^{19}$. Istotne było dla niego życie i doświadczenia bohaterów, dlatego, na ile to było możliwe, zrekonstruował życie pazia, przywołując historię ofiary, która nie miata prawa do Historii ${ }^{20}$, a całą drugą część książki poświęcił życiu biskupa. To nie jest sucha, obiektywna historyczna rekonstrukcja. To opowieść napisana z emocjonalnym zaangażowaniem, z perspektywy dużego dystansu czasowego. W artykule Żałoba i postpamięć Marianne Hirsch pisze: Postpamięć jest silnq i bardzo szczególna forma pamięci wtaśnie dlatego, że jej relacja wobec przedmiotu czy źródta jest zapośredniczona nie poprzez wspomnienia, ale wyobraźnię i twórczośc ${ }^{21}$.

Rozważmy także tezę, że Francisco Núñez Roldán funkcjonuje jako dający niebezpośrednie świadectwo secondary witness (świadek wtórny), posługując się pojęciem, które ukuli w odniesieniu do świadectw Zagłady Lawrence Langer i Terrence des Pres ${ }^{22}$. Wobec odchodzenia osób, które przeżyły Holokaust, a więc gasnącej możliwości przekazywania ich wspomnień poprzez bezpośredni kontakt, alternatywą może być „odtworzenie jako pamięci" materiałów zgromadzonych w archiwach. Innymi słowy, oparty na autorefleksji podmiotu renesans cudzych wspomnień. W tym kontekście objawia się rola secondary witness ${ }^{23}$. Koncepcja ta nie ma generacyjnego limitu - każdy człowiek może się znaleźć na pozycji secondary witness jako empatyczny słuchacz, widz lub czytelnik ${ }^{24}$. Jedyną formą, dzięki której nawiązuje on afektywne połączenie z przeszłością są jej symboliczne reprezentacje - obrazy, nagrania, teksty. Reprezentacje te wpływają na jego życie i system wartości - niemal tak intensywnie, jak wydarzenia przeżyte osobiście - i stymulują go do działania, do przetwarzania doświadczenia.

Tak właśnie stało się w przypadku autora książki El pecado nefando del obispo de Salamina, który pozwolił ożyć pamięci zdarzeń sprzed niemal czterech i pół wieku. Jego starania trafily na podatny grunt, biorąc pod uwagę, że publiczna debata o roli Kościoła - jego powinnościach, wizerunku i wypaczeniach - trwa obecnie na całym świecie. Ricardo García Cárcel podkreśla jednak, że pobierając lekcje z przeszłości należy pamiętać, by poddawać rewizji dialektyczną relację przeszłości i teraźniejszości, bowiem

\footnotetext{
M. Hirsch, The Generation of Postmemory: Writing..., s. 36.
}

19 F. Núñez Roldán, El Pecado Nefando..., s. 16.

20 Ewa Domańska podkreśla, że historie zwykłych ludzki, którzy nie mieli wpływu na kształtowanie się narracji historycznych, stają się coraz częściej przedmiotem badań nowej humanistyki. Zob. E. Domańska, Wprowadzenie, [w:] Teoria wiedzy o przesztości na tle wspótczesnej humanistyki. Antologia, red. E. Domańska, Poznań 2010, s. 13.

21 M. Hirsch, Żałoba i postpamięć, przeł. K. Bojarska, [w:] Teoria wiedzy o przesztości..., s. 254.

22 Zob. G. Hartman, Shoah and Intellectual Witness, „Partisan Review” 1998, nr 1, s. 38.

23 Zob. A. Assmann, The Empathetic Listener and the Ethics of Storytelling, [w:] Storytelling and Ethics. Literature, Visual Arts and the Power of Narrative, red. H. Meretoja, C. Davies, Routledge 2017.

24 O tym szczególnym wymiarze empatii, o którym jest tutaj mowa, pisały m.in.: Jill Bennett w książce Empathic Vision: Affect, Trauma, and Contemporary Art, Stanford 2005, s. 55-56 oraz Alison Landsberg w eseju Memory, Empathy, and the Politics of Identification, [w:] „International Journal of Politics, Culture, and Society” 2009, vol. 22, nr 2 („Special Issue: Memory and Media Space”), s. 221-229. 
ani historia się nie powtarza, ani sytuacje, ani ich bohaterowie (...). Powtarzalna jest jedynie kondycja ludzka $a^{25}$. Warto w tym kontekście przywołać także pojęcie „intrahistorii”, neologizm stworzony przez Miguela de Unamuno, oznaczający - wedle słownikowej definicji - zwyczajne życie, które stuży za tto zmieniającej się w widoczny sposób historii ${ }^{26}$. Sam autor wyjaśnia jego naturę, odwołując się do metafory morskiej, w której pisze o falach historii i gtębinach intrahistorii ${ }^{27}$. Z kolei Núñez Roldán ukazuje rolę czynnika religijnego w życiu społecznym, mając świadomość, że w Hiszpanii średniowiecznej i wczesnonowożytnej jedność wyznaniowa, a co za tym idzie wspólnota wartości duchowych, była utożsamiana z jednością państwa. Wiara stanowiła jego siłę kreacyjną, fenomen uwewnętrzniony na tyle, że niekoniecznie nawet poddawany świadomej refleksji. W tym samym duchu Unamuno opisywał intrahistorię, określając ją mianem wiecznej tradycji lub prawdziwej tradycji i dodając że tak, jak tradycja jest substancją historii, wieczność jest substancją czasu ${ }^{28}$. Nasuwa się analogiczne pytanie: Czy za substancję pamięci może zostać uznany jej ponadpokoleniowy przekaz?

Przechodząc do konkluzji, pragnę zaznaczyć, że moją intencją jako autorki niniejszego artykułu była z jednej strony próba zbadania, czy powstanie książki Francisca Núñeza Roldána można traktować jako przejaw funkcjonowania postpamięci, z drugiej zaś uczynienie nieznanego dotąd w Polsce „przypadku z Estremadury” i jego studium przyczynkiem do dyskusji na temat posłannictwa historyka w kontekście postpamięciowego dyskursu. Nie jest ono czymś oczywistym, historyka często postrzega się jako surowego krytyka źródeł cennych dla postpamięciowych narracji, takich jak archiwa historii mówionej lub kolekcje fotografiii ${ }^{29}$. Choć Núñez Roldán korzystał z dokumentów procesowych, których wiarygodność trudno kwestionować, myślę, że jego empatyczna postawa, która doprowadziła do napisania i publikacji utworu El pecado nefando de obispo de Salamina daje nadzieję na możliwą ewolucję postaw w tym obszarze.

\section{BIBLIOGRAFIA}

Assmann A., The Empathetic Listener and the Ethics of Storytelling, [w:] Storytelling and Ethics. Literature, Visual Arts and the Power of Narrative, red. H. Meretoja, C. Davies, Routledge 2017, https://doi.org/10.4324/9781315265018.

Bennett J., Empathic Vision: Affect, Trauma, and Contemporary Art, Stanford 2005.

Campillo de Llerena rescata en una obra de teatro la historia del Obispo de Salamina ante la Santa Inquisición, „El Diario” 2015, 27 VII, [online] https://www.eldiario.es/eldiarioex/cultura/ Campillo-Llerena-Obispo-Salamina-Inquisicion_0_413659070.html, 21 VIII 2018.

\footnotetext{
25 R. García Cárcel, La herencia..., s. 17.

26 RAE, [online]: http://dle.rae.es/?id=Lynu9Mx, 24 XII 2016.

27 Zob. M. de Unamuno, Obras completas, I. Paisajes y ensayos, Madrid 1966, s. 793.

28 Tamże, s. 792-793.

29 L. Quílez Esteve, Hacia una teoría..., s. 66.
} 
Dokumenty Soborów Powszechnych: tekst taciński i polski, t. 4: (1511-1870): Lateran V, Trydent, Watykan I, oprac. A. Baron, H. Pietras, przeł. A. Baron i in., Kraków 2004.

Domańska E., Teoria wiedzy o przesztości na tle wspótczesnej humanistyki. Antologia, red. E. Domańska, Poznań 2010.

García Cárcel R., La herencia del pasado. Las memorias históricas de España, Barcelona 2011.

Hartman G., Shoah and Intellectual Witness, „Partisan Review” 1998, nr 1.

Hirsch M., Past Lives: Postmemories in Exile, „Poetics Today” 1996, vol. 17, nr 4, https://doi. org/10.2307/1773218.

Hirsch M., The Generation of Postmemory, „Poetics Today” 2008, vol. 29, nr 1, https://doi. org/10.1215/03335372-2007-019.

Hirsch M., The Generation of Postmemory: Writing and Visual Culture After the Holocaust, New York 2012, https://doi.org/10.5749/minnesota/9780816674695.003.0009.

Hirsch M., Żałoba i postpamięć, przeł. K. Bojarska, [w:] Teoria wiedzy o przesztości na tle wspótczesnej humanistyki. Antologia, red. E. Domańska, Poznań 2010.

Hoffman E., After Such Knowledge, New York 2004.

Kamen H., Inkwizycja hiszpańska, przeł. K. Bażyńska-Chojnacka, P. Chojnacki, Warszawa 2005.

Landsberg A., Memory, Empathy, and the Politics of Identification, „International Journal of Politics, Culture, and Society” 2009, vol. 22, nr 2 („Special Issue: Memory and Media Space”), https://doi.org/10.1007/s10767-009-9056-x.

Moreno D., La construcción del mito de la Inquisición, „Andalucía en la Historia” 2013, nr 39, [online] https://www.centrodeestudiosandaluces.es/index.php?mod=publicaciones\&cat= 23\&id=2684\&idm=, 30 IV 2019.

Núñez Roldán F., El Pecado Nefando del Obispo de Salamina. Un Hombre sin Concierto en la Corte de Felipe II, Sevilla 2002.

Quílez Esteve L., Hacia una teoria de la posmemoria. Reflexiones en torno a las representaciones de la memoria generacional, „Historiografías” 2014, nr 8, https://doi.org/10.26754/ ojs_historiografias/hrht.201482417.

Rawlings H., Inkwizycja hiszpańska, przeł. M. Piątek, Kraków 2009.

REAL ACADEMIA ESPAÑOLA, Diccionario de la lengua española, [online] http://dle.rae. es/?id=Lynu9Mx, 24 XII 2016.

Unamuno M. de, Obras completas, I. Paisajes y ensayos, Madrid 1966.

Dr Kamila ŁAPICKA - teatrolożka, badaczka teatru, pasjonatka dramatu współczesnego. W 2016 roku zdobyła pierwszą nagrodę (ex aequo) w III edycji Ogólnopolskiego Konkursu im. Andrzeja Żurowskiego na recenzje teatralne dla młodych krytyków. W 2019 roku obroniła w Instytucie Studiów Iberyjskich i Iberoamerykańskich Uniwersytetu Warszawskiego rozprawę doktorską poświęconą dramatom historycznym Juana Mayorgi. Doktorantka w Centrum im. Mordechaja Anielewicza na Wydziale Historycznym Uniwersytetu Warszawskiego, gdzie zajmuje się badaniem działań Inkwizycji hiszpańskiej wobec konwertytów żydowskich. 